\title{
Recommendations for the nutrition management of phenylalanine hydroxylase deficiency
}

\author{
Rani H. Singh, PhD, RD1, Fran Rohr, MS, RD², Dianne Frazier, PhD, $\mathrm{MPH}^{3}$, \\ Amy Cunningham, MS, RD ${ }^{4}$, Shideh Mofidi, MS, RD ${ }^{5}$, Beth Ogata, MS, RD ${ }^{6}$, \\ Patricia L. Splett, PhD, MPH${ }^{7}$, Kathryn Moseley, MS, RD ${ }^{8}$, Kathleen Huntington, MS, $\mathrm{RD}^{9}$, \\ Phyllis B. Acosta, DrPH, RD ${ }^{10}$, Jerry Vockley, MD, PhD ${ }^{11,12}$ and Sandra C. Van Calcar, PhD, RD ${ }^{13}$
}

The effectiveness of a phenylalanine-restricted diet to improve the outcome of individuals with phenylalanine hydroxylase deficiency (OMIM no. 261600) has been recognized since the first patients were treated 60 years ago. However, the treatment regime is complex, costly, and often difficult to maintain for the long term. Improvements and refinements in the diet for phenylalanine hydroxylase deficiency have been made over the years, and adjunctive therapies have proven to be successful for certain patients. Yet evidence-based guidelines for managing phenylalanine hydroxylase deficiency, optimizing outcomes, and addressing all available therapies are lacking. Thus, recommendations for nutrition management were developed using evidence from peer-reviewed publications, gray literature, and consensus surveys. The areas investigated included choice of appropriate medical foods, integration of adjunctive therapies, treatment during pregnancy, monitoring of nutritional and clinical markers, prevention of nutrient deficiencies, providing of access to care, and compliance strategies. This process has not only provided assessment and refinement of current nutrition management and monitoring recommendations but also charted a direction for future studies. This document serves as a companion to the concurrently published American College of Medical Genetics and Genomics guideline for the medical treatment of phenylalanine hydroxylase deficiency.

Genet Med advance online publication 2 January 2014

Key Words: medical food; nutrition management of $\mathrm{PAH}$ deficiency; nutrition recommendations; phenylalanine hydroxylase deficiency; phenylketonuria
Nutrition therapy, first introduced 6 decades ago, remains the primary treatment for phenylalanine hydroxylase (PAH) deficiency. ${ }^{1-3}$ The goals of lifelong nutrition therapy include normal physical growth and neurocognitive development, maintenance of adult health, and normal gestational outcomes in pregnant women with PAH deficiency. Knowledge of metabolism, the pathophysiology of PAH deficiency, and the role of nutrition has led to new and improved treatment options, modified lowprotein foods, and medical foods that provide protein equivalents and other nutrients when intact protein food sources must be limited. Table 1 contains definitions of modalities used in the nutrition treatment of aminoacidopathies, including $\mathrm{PAH}$ deficiency. Lifelong treatment is recommended because of the negative association between elevated blood phenylalanine (PHE) and neurocognition, yet national nutrition recommendations for PAH deficiency are lacking. The goals of the present evidence- and consensus-based recommendations are to translate current knowledge to patient care, foster more harmonious clinical practices, and promote healthy eating, with the ultimate goal of ensuring better outcomes for individuals with PAH deficiency. This document serves as a companion to the concurrently published American College of Medical Genetics and Genomics (ACMG) guideline for the medical treatment of PAH deficiency. ${ }^{4}$

\section{MATERIALS AND METHODS}

Recommendations were developed by a cooperative effort among Genetic Metabolic Dietitians International, the Southeast Regional Genetics Collaborative, and dietitians from the Diet Control and Management and Maternal PKU Workgroups from the National Institutes of Health Phenylketonuria Scientific Review Conference ${ }^{2}$ held in February 2012. The evidence for these recommendations represents the synthesis of information from the National Institutes of Health 2000 (ref. 2) and Agency for Healthcare Research and Quality 2012 (ref. 1) reviews and the literature review completed by the National Institutes of Health Phenylketonuria Scientific Review Conference workgroups. PubMed was the primary database for the National Institutes of

\footnotetext{
${ }^{1}$ Division of Medical Genetics, Department of Human Genetics, Emory University School of Medicine, Atlanta, Georgia, USA; ${ }^{2}$ Division of Genetics and Metabolism, Boston Children's Hospital, Boston, Massachusetts, USA; ${ }^{3}$ Department of Pediatrics, University of North Carolina at Chapel Hill, Chapel Hill, North Carolina, USA; ${ }^{4}$ Hayward Genetics Center, Tulane University School of Medicine, New Orleans, Louisiana, USA; ${ }^{5}$ Inherited Metabolic Disease Center, Maria Fareri Children's Hospital, Westchester Medical Center, New York Medical College, Valhalla, New York, USA; ${ }^{6}$ Department of Pediatrics, University of Washington, Seattle, Washington, USA; ${ }^{7}$ Splett \& Associates, Stanchfield, Minnesota, USA; ${ }^{8}$ Department of Pediatrics, University of Southern California Medical Center, Los Angeles, California, USA; ${ }^{9}$ Metabolic Clinic, Institute for Development and Disability, Oregon Health Science University, Portland, Oregon, USA; ${ }^{10}$ Private practice, Atlanta, Georgia, USA; ${ }^{11}$ Department of Pediatrics, University of Pittsburgh School of Medicine, Pittsburgh, Pennsylvania, USA; ${ }^{12}$ Department of Human Genetics, University of Pittsburgh School of Medicine, Pittsburgh, Pennsylvania, USA; ${ }^{13}$ Division of Genetics and Metabolism, Department of Pediatrics, University of Wisconsin School of Medicine and Public Health, Madison, Wisconsin, USA. Correspondence: Rani H. Singh (rsingh@genetics.emory.edu) 
Table 1 Definitions of modalities used for treatment of aminoacidopathies

\begin{abstract}
Medical food: A food that is formulated to be consumed or administered enterally under the supervision of a physician and that is intended for the specific dietary management of a disease or condition for which distinctive nutritional requirements, based on recognized scientific principles, are established by medical evaluation (section 5(b), Orphan Drug Act (21 USC 360ee (b)(3)61)).

Modified low-protein food: Food products specially formulated to contain less than $1 \mathrm{~g}$ of protein per serving. Low-protein modified food products are intended for use under the direction of a physician for the dietary treatment of hereditary metabolic diseases. Examples of commercially available lowprotein food products include breads, pasta, baking mix, and imitation cheese.

Intact protein: Food-derived, natural protein.

Protein equivalent: Containing an equivalent amount of nitrogen as found in a complete protein. For medical foods, this is often used to describe the free amino acids that replace intact protein.
\end{abstract}

Health Phenylketonuria Scientific Review Conference scientific literature searches. Search terms were specific to each question (as described in the ACMG guideline ${ }^{4}$ ), but inclusion and exclusion criteria were the same for all questions.

Consensus-based tools used to support these recommendations were the National Institutes of Health expert panel summary (described in the companion paper), a PAH Deficiency Delphi survey, ${ }^{5}$ and an Inborn Errors of Metabolism (IEM) survey (D.M. Frazier, S.C. van Calcar, et al., personal communication). The Delphi process is a component of the guideline development model that uses accepted methods for evidence analysis, with the addition of consensus techniques to address clinical practice issues for which research is lacking. ${ }^{6}$ The Delphi survey, an online survey in which participants indicated their level of agreement or disagreement with practice statements, was answered by 17 experts from the seven Health Resources and Services Administration Regional Genetics and Newborn Screening Collaboratives. When the level of agreement was $80 \%$ or greater, the information was added to the evidence summaries in these recommendations. The IEM survey, also online, was conducted following the National Institutes of Health-sponsored Nutrition and Dietary Supplement Interventions for Inborn Errors of Metabolism Workshop that was held in December 2011. Information about the use of nutritional treatments and supplements by metabolic specialists managing individuals with PAH deficiency was collected from 82 survey respondents.

\section{BLOOD PHE AND TYROSINE (TYR) CONTROL Target blood PHE}

Blood PHE has been used to monitor metabolic status and determine appropriate dietary PHE intake and has been shown to be a reliable predictor of clinical outcomes. ${ }^{7}$ The companion ACMG PAH deficiency treatment guideline supports a lifelong target blood PHE of 120-360 $\mu \mathrm{mol} / \mathrm{l}$ for optimal cognitive outcome. ${ }^{4}$ Eighty percent of Delphi respondents supported $120-360 \mu \mathrm{mol} / \mathrm{l}$ as a goal blood PHE for individuals with PAH deficiency of all ages, yet there was recognition that the goal is difficult to achieve and may not apply in all cases. ${ }^{5}$ Regular blood PHE monitoring is key to the management of PAH deficiency. During infancy, early childhood, and pregnancy, more frequent monitoring is necessary to assess the increased dietary PHE needs of anabolism ${ }^{3}$ (Table 2). The British Medical Research Council guidelines recommend measuring PHE concentrations at a standard time ${ }^{3}$; there was a consensus that blood samples be collected at the same time of day, preferably 2-3 hours after a meal. ${ }^{5}$ It is recommended that medical food be consumed throughout the day to maintain stable concentrations of blood PHE. ${ }^{8}$

\section{Target blood TYR and PHE:TYR ratio}

Because both endogenous production of TYR and intact protein intake are greatly limited in PAH deficiency, monitoring is necessary to ensure that supplementation is adequate to maintain the blood TYR in the normal range. Some clinicians routinely monitor blood PHE:TYR ratios. ${ }^{9}$ There are reports of impairments in executive function among individuals with high PHE:TYR ratios. ${ }^{9} 10$ However, at this time the clinical relevance of PHE:TYR as a routine biomarker requires further study.

\section{RECOMMENDATIONS}

- Maintain blood PHE between 120 and $360 \mu \mathrm{mol} / \mathrm{l}$ throughout the life span for optimal outcome.

- Monitor blood PHE most frequently during times of increased anabolism: infancy, childhood, and pregnancy.

- Monitor blood PHE at a consistent time during the day, preferably 2-3 hours after eating.

- Maintain blood TYR in the normal range.

\section{THE INFLUENCE OF GENOTYPE ON NUTRITION TREATMENT}

As described in the ACMG guideline, ${ }^{4}$ individuals with $\mathrm{PAH}$ deficiency have been categorized by phenotype (PHE tolerance and blood PHE concentrations) and genotype. ${ }^{4} \mathrm{PHE}$ tolerance is defined as the amount of dietary PHE (mg/day) an individual with PAH deficiency can consume while maintaining blood PHE in the treatment range. ${ }^{11}$ Although individuals with PAH deficiency are represented by a spectrum of residual enzyme activity, some practitioners find practical utility in referring to the older categories: "classic/severe," "moderate," "mild," and "mild hyperphenylalaninemia not needing PHE restriction."

\section{Treatment by phenotype and PHE tolerance}

In clinical practice, PHE tolerance can often be determined by 2-5 years of age. ${ }^{12}$ However, because PHE tolerance can change during periods of rapid growth or changes in lifestyle, 
Table 2 Monitoring the nutritional management of individuals with PAH deficiency ${ }^{\mathrm{a}}$

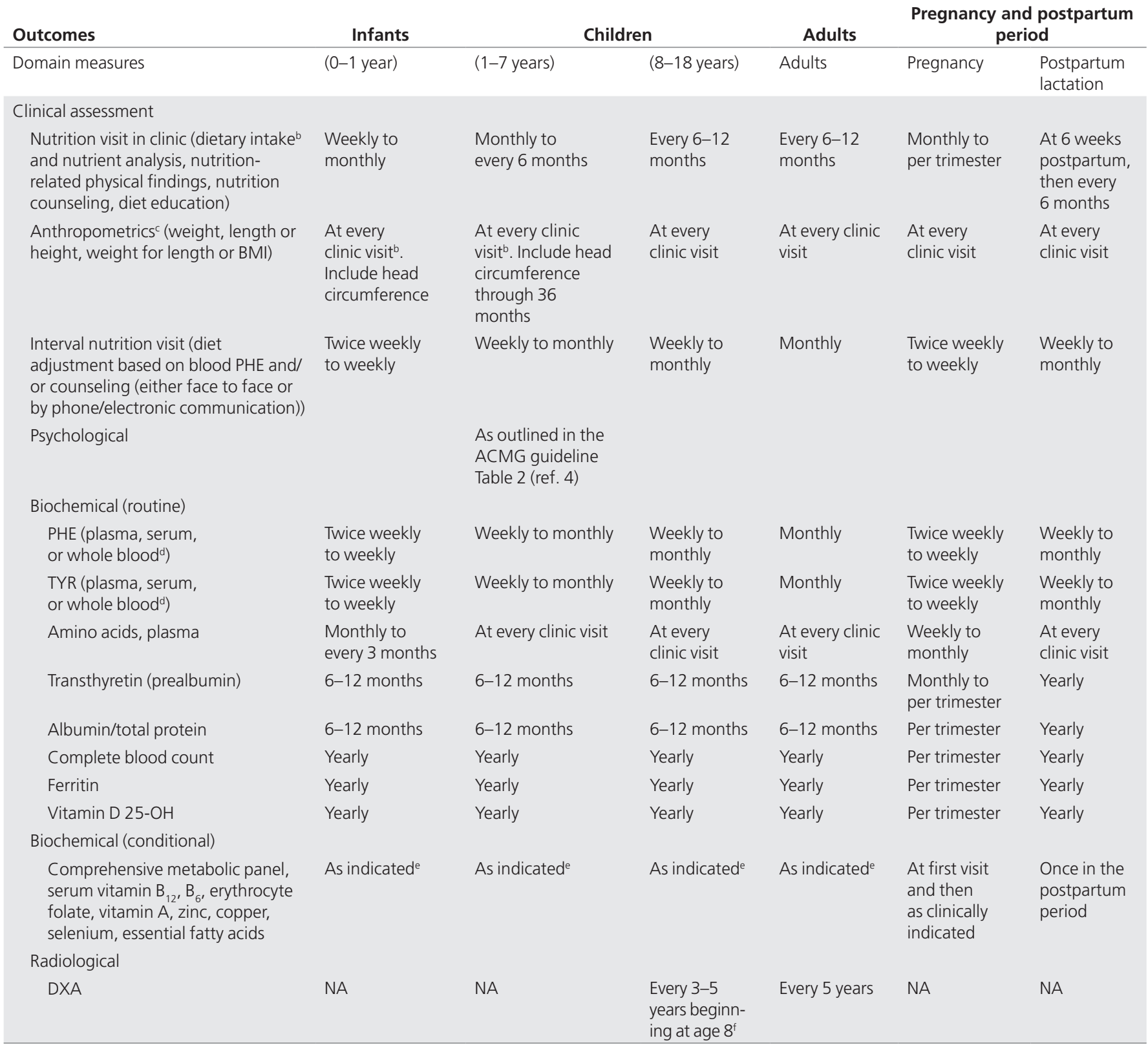

ACMG, American College of Medical Genetics and Genomics; BMI, body mass index; DXA, dual-energy X-ray absorptiometry; NA, not applicable; PAH, phenylalanine hydroxylase; PHE, phenylalanine; TYR, tyrosine.

aRecommendations were derived from Delphi and Nominal group consensus on monitoring of aminoacidopathies and the Newborn Screening Translational Research Network. Frequency of clinical and laboratory assessments at a metabolic clinic (involving the medical geneticist, metabolic dietitian, social worker, nurse specialist, psychologist, and others) may not be possible for reasons such as travel distance, cost, and loss of work days. Coordination with primary-care and community-based providers, use of telemedicine, and frequent communication by telephone and mail should be employed. More frequent monitoring may be necessary if the individual is not in good metabolic control.

${ }^{b} \mathrm{~A}$ mechanism for assessing dietary intake, whenever PHE is monitored, should be in place. MetabolicPro (http://www.metabolicpro.org) is a computer program available for dietary analysis of amino acid-restricted diets.

cThe Centers for Disease Control and Prevention (CDC) recommends using the 2006 World Health Organization (WHO) Child Growth Standards to evaluate growth of infants from birth to age 24 months. The CDC recommends using the 2000 CDC Growth Charts to evaluate the growth of children from age 2 to 20 years. Techniques for measurement are described on the CDC website (http://www.cdc.gov/growthcharts/cdc_charts.htm).

¿Monitoring protocols may include mail-in blood specimens (using filter paper cards or capillary tubes) or use of local laboratories or the State Laboratory of Public Health. Such protocols are optimal for increasing the frequency of monitoring. When plasma amino acid analysis is the only available means of PHE and TYR monitoring, access and cost may force less-frequent monitoring.

eMonitoring is indicated when nutrition assessment indicates poor adherence to diet or inadequate medical food consumption, or when there has been consumption of an incomplete medical food, clinical signs/symptoms of nutritional inadequacy including poor growth, or serious intercurrent illness. If laboratory values are abnormal, reassessment of specific analytes should be scheduled within 1 month of intervention.

${ }^{\mathrm{f} D X A}$ is indicated in individuals who have frequent fractures and/or low serum 25-hydroxy vitamin D concentrations. 
it is important to reassess PHE tolerance periodically by assessing dietary PHE intake with blood PHE. ${ }^{11,13}$ Predicting PHE tolerance may be useful when communicating expectations to families, assessing responsiveness to adjunctive therapy, ${ }^{14}$ and planning dietary prescriptions.

Those with little residual PAH activity ("classic PKU") will require the most medical food as their primary source of protein equivalents. ${ }^{15}$ Modified low-protein foods should be introduced early to meet critical energy needs and maintain metabolic control in this group. For individuals with mild or moderate PAH deficiency, less medical food and/or modified low-protein food is needed to maintain blood PHE control. ${ }^{16}$ Such individuals are also more likely to respond to sapropterin, which has the potential for allowing liberalization of the diet. The need to treat individuals with very mild hyperphenylalaninemia remains under debate. ${ }^{17}$

Even with classification by genotype or phenotype, additional factors can affect the management of PAH deficiency. Individualized treatment plans must reflect the patient's unique genetic makeup, general health, intercurrent illness, growth requirements, activity level, pregnancy/lactation status, and access to care.

\section{NUTRIENT REQUIREMENTS, SOURCES, AND MONITORING}

Nutrient requirements for individuals with $\mathrm{PAH}$ deficiency do not differ from those of the general population, except for PHE, TYR, and protein (Table 3). ${ }^{3,18-20}$ Concern about the nutritional adequacy of the diet arises because the severe restriction of foods containing intact protein necessitates lifelong reliance on semisynthetic medical foods, from which some nutrients may not be as well absorbed. In addition, nonadherence to medical food consumption, or reliance on nutritionally incomplete medical foods, increases the risk of multiple nutrient deficiencies. Therefore, monitoring of nutrient intake and laboratory indexes of nutritional adequacy is recommended (Table 2).

\section{Protein and amino acids}

Because medical food is the primary source of protein equivalents in the diet for PAH deficiency, it is a critical component of the diet throughout life. Recommendations for total protein intake exceed age- and sex-specific Dietary Reference Intakes because $\mathrm{L}$-amino acids found in most medical foods are absorbed and oxidized more rapidly than amino acids in intact protein. ${ }^{21,22}$ Traditionally, L-amino acids (without PHE) have been the source of protein equivalents in medical foods, but more recently, glycomacropeptide (GMP), an intact protein that is low in PHE, has been used as a protein source in combination with limiting L-amino acids. ${ }^{23} \mathrm{~L}$-Amino acid-based or GMP-based medical foods provide $~ 85 \%$ of the protein needs of individuals with a severe form of PAH deficiency. ${ }^{24}$ Large neutral amino acids (LNAAs) can also be used as the medical food for some individuals with PAH deficiency in conjunction with a more relaxed protein restriction.

Normal protein status, assessed by monitoring plasma amino acids and prealbumin, is achievable when total protein is

Table 3 Recommended intakes of PHE, TYR, and protein for individuals with PAH deficiency

\begin{tabular}{|c|c|c|c|}
\hline Age & PHE (mg/day) & TYR (mg/day) & Protein $^{a}(\mathrm{~g} / \mathrm{kg})$ \\
\hline \multicolumn{4}{|l|}{ Infant to $<4$ years ${ }^{b}$} \\
\hline 0 to $<3$ months ${ }^{c}$ & $130-430$ & $1,100-1,300$ & $3-3.5$ \\
\hline 3 to $<6$ months & $135-400$ & $1,400-2,100$ & $3-3.5$ \\
\hline 6 to $<9$ months & $145-370$ & $2500-3000$ & $2.5-3$ \\
\hline 9 to $<12$ months & $\begin{array}{l}135-330 \\
\text { (mg/day) }\end{array}$ & $\begin{array}{c}2,500-3,000 \\
\text { (mg/day) }\end{array}$ & $\begin{array}{c}2.5-3 \\
\text { (g/day) }\end{array}$ \\
\hline$>4$ years to adult & $200-1,100$ & $4,000-6,000$ & $120-140 \%$ RDA for age \\
\hline \multicolumn{4}{|l|}{ Pregnancy/lactation ${ }^{9}$} \\
\hline Trimester 1 & $265-770$ & $6,000-7,600$ & $\geq 70$ \\
\hline Trimester 2 & $400-1,650$ & $6,000-7,600$ & $\geq 70$ \\
\hline Trimester 3 & $700-2,275$ & $6,000-7,600$ & $\geq 70$ \\
\hline
\end{tabular}

DRI, dietary reference intake; PAH, phenylalanine hydroxylase; PHE, phenylalanine; RDA, recommended dietary allowance;TYR, tyrosine.

aprotein recommendations for individuals consuming PHE-free amino acid-based medical foods as part of their protein source.

${ }^{b}$ Recommended intakes for infants and children $<4$ years of age are adapted from ref. 20 and are for individuals with a severe form of PAH deficiency treated with a PHErestricted diet alone.

'PHE requirements for premature infants with $\mathrm{PAH}$ deficiency may be higher.

dPHE tolerance is usually stable by $2-5$ years of age as PHE requirements are based on a combination of size (increasing with age) and rate of growth (decreasing with age). For any individual, PHE intake is adjusted based on frequent blood PHE monitoring.

eAdapted from ref. 12. Range of PHE intake is for entire spectrum of PAH deficiency (mild to severe).

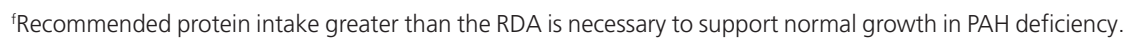

gRecommendations are slightly higher for pregnant women $\leq 19$ years of age.

hDRI recommends that, for all women, nutrient intake during lactation be the same as during the third trimester of pregnancy. 
provided in appropriate amounts. ${ }^{18,21}$ Prealbumin is an acceptable measure of protein status in individuals with $\mathrm{PAH}$ deficiency. ${ }^{25}$ Mild protein insufficiency, as indicated by a prealbumin concentration of $<20 \mathrm{mg} / \mathrm{dl}$, has been associated with decreased linear growth. ${ }^{26}$

TYR is conditionally essential in PAH deficiency and must be added to the diet to maintain blood concentrations in the normal range. By itself, TYR supplementation does not improve neurological outcomes. ${ }^{27}$ All medical foods for the treatment of PAH deficiency are supplemented with TYR; ${ }^{15}$ therefore, individuals who do not adhere to their prescribed intake of medical food may have inadequate blood concentrations of TYR. In addition, TYR has a low solubility and may settle out of prepared medical foods during storage. ${ }^{15}$ Most clinicians monitor blood TYR routinely in individuals with PAH deficiency, ${ }^{9}$ and low plasma TYR has been documented among individuals treated with $\operatorname{diet}^{28}$ One cause could be a diurnal variation in blood TYR. ${ }^{29}$ Supplementation beyond that provided by medical food with TYR is indicated only if blood TYR concentrations are consistently below the normal range. Fewer than $20 \%$ of clinicians in the IEM survey (D.M. Frazier, S.C. van Calcar, et al., personal communication) routinely prescribe TYR supplementation.

\section{Energy}

Because energy expenditure varies from person to person, energy requirements must be individually assessed. Most evidence suggests that energy requirements are not increased in $\mathrm{PAH}$ deficiency, and carbohydrate and fat intakes are within established recommendations. ${ }^{30,31}$

\section{Essential fatty acids}

With adequate fat intake, children with PAH deficiency are found to have normal essential fatty acid (EFA) status. ${ }^{32}$ Medical foods supplemented with sources of long-chain polyunsaturated fatty acids increase blood concentrations of EFA. ${ }^{33}$ When a fatfree medical food is provided or the diet contains inadequate sources of linoleic and $\alpha$-linolenic acid, EFA status should be monitored. ${ }^{5}$ Both the IEM survey (D.M. Frazier, S.C. van Calcar, et al., personal communication) and the Delphi survey ${ }^{5}$ suggest that supplementation with precursor EFA, or with preformed docosahexaenoic acid (DHA), may be necessary in these individuals. In infancy, including breast milk or standard formulas containing DHA and arachidonic acid, as well as medical foods that contain DHA/arachidonic acid, can help ensure adequacy.

\section{Micronutrients}

Most medical foods available in the United States are supplemented with vitamins and minerals to provide micronutrients in amounts that meet recommendations. When a medical food does not contain adequate amounts of micronutrients or an individual's intake is inadequate, a vitamin and mineral supplement should be included in the treatment plan. Additional biochemical monitoring (Table 2) is indicated when there is a question about inadequate or excessive intake.
Minerals, including copper, manganese, and zinc, ${ }^{34}$ as well as selenium, ${ }^{35}$ have been reported as being deficient in the diet for PAH deficiency. However, these minerals are now added to most medical foods. Iron deficiency (without anemia) has been reported among individuals with PAH deficiency, and routine evaluation of iron status is recommended. ${ }^{36,37}$

Vitamin $B_{12}$, as well as $B_{6}$, deficiency may occur if there is inadequate consumption of medical food or animal protein..$^{38}$ Severe megaloblastic anemia has been reported in adolescents and adults with PAH deficiency who are offdiet. ${ }^{39}$ Because $B_{12}$ deficiency can cause neurological deficits, ${ }^{40}$ including memory loss, such symptoms could be erroneously attributed to high blood PHE. Supplementation is indicated if $B_{12}$ markers remain low. ${ }^{40}$ In addition, higher than normal plasma $B_{12}$ levels have been reported in some on-diet individuals with PAH deficiency. ${ }^{41}$ Both excessive and inadequate intakes of the fat-soluble vitamins A and $\mathrm{D}$ are possible with inappropriate medical food intake. Monitoring for clinical signs with subsequent biochemical testing is warranted.

There may be concerns with bone density that are unique to PAH deficiency. Decreased bone mineral density and bone mineral content, indicated by dual-energy X-ray absorptiometry, have been noted. ${ }^{42,43}$ Osteopenia, defined as bone mineral density one or more SDs from normal reference for age and sex, is also seen ${ }^{44}$ but cannot be attributed to vitamin D concentrations alone. Some reports indicate that bone density is associated with adherence to nutrition therapy, ${ }^{45}$ whereas others note decreased density across groups, stratified by calcium and phosphorus intakes ${ }^{42}$ and/or as compared with controls without PAH deficiency. ${ }^{43}$ Aberrant findings in protein markers, correlating to bone resorption or absorption, have also been reported. ${ }^{46,47}$ Further research is warranted to look at the effects of PAH deficiency itself, PAH deficiency management, and nutrient intake on bone density.

\section{Anthropometrics}

With adequate nutrient intake, appropriate growth can be expected for individuals with PAH deficiency. ${ }^{18,19}$ Impaired linear growth has been noted in children with PAH deficiency who had low plasma prealbumin concentrations. ${ }^{26}$ There is conflicting evidence as to whether or not the rates of overweight and obesity in children with PAH deficiency are similar to those of the general population. ${ }^{30,48}$

\section{Clinical indicators}

Physical findings associated with poorly controlled PAH deficiency include osteopenia ${ }^{45}$ and dermatological problems. ${ }^{49}$ Asthma, recurrent headache, eczema, neurological signs, hyperactivity, and/or lethargy have all been reported in adults with PAH deficiency who discontinued dietary treatment. ${ }^{50}$ Psychological symptoms include phobias and depression..$^{51}$ The majority of physical signs and symptoms of PAH deficiency reported in the literature resolved when blood PHE concentrations were reduced to the treatment range. 


\section{RECOMMENDATIONS}

- Provide the same nutrient intakes as those of the general population, except for PHE, TYR, and protein.

- Assess the need for vitamin/mineral supplementation when a medical food without complete vitamins and minerals is used or when there is insufficient adherence with medical food intake.

- Monitor nutrition status by assessing anthropometrics, clinical signs and symptoms, nutrient intake, and laboratory indexes of metabolic control and nutrition adequacy (Table 2).

\section{NUTRITION STRATEGIES FOR MANAGEMENT OF INDIVIDUALS WITH PAH DEFICIENCY}

\section{Selecting medical food}

Medical foods provide necessary protein equivalents in the diets of individuals with $\mathrm{PAH}$ deficiency, and selecting the appropriate medical food can affect both dietary compliance and nutritional status. There are more than 30 medical foods available for the treatment of PAH deficiency, and they can be classified by the age for which they are intended and by macronutrient composition (Table 4). Infant medical foods typically lack only PHE. Products designed for children, adolescents, and adults vary widely in protein, fat, vitamin, and mineral content to meet individual taste and nutrient needs, but many are nutritionally incomplete. The macroand micronutrient profiles of many medical foods for IEM are available at http://www.gmdi.org. Medical food should be consumed throughout the day and divided into at least three servings because more frequent consumption of medical foods is associated with better PHE tolerance ${ }^{13}$ and improved plasma PHE concentrations. ${ }^{8}$

Medical foods are available in a variety of flavors and in different forms (i.e., powders, ready-to-drink liquids, tablets, and bars). Convenience packaging and alternative forms of medical foods typically cost more than the powdered forms. Although insurance coverage of medical foods is mandated in some states, there are exceptions and limitations. Therefore, access to medical food is not guaranteed in the United States, and obtaining coverage can be an arduous process. ${ }^{52}$ This is due, in part, to the fact that medical foods are not prescription medications but have a unique classification by the Food and Drug Administration that was intended to promote the development of more products for PAH deficiency and other orphan diseases. ${ }^{53}$ The classification allows a less costly regulatory process necessary to get medical foods to market.

Table 4 Classification of medical foods ${ }^{a}$

\begin{tabular}{|c|c|c|c|c|c|}
\hline Classification & $\begin{array}{l}\text { Amino acids, fat, } \\
\text { carbohydrate,vitamins, } \\
\text { and minerals }\end{array}$ & $\begin{array}{l}\text { Amino acids, } \\
\text { carbohydrate, vitamins, } \\
\text { and minerals }\end{array}$ & Amino acids & Glycomacropeptide & $\begin{array}{c}\text { Large } \\
\text { neutral } \\
\text { amino acids }\end{array}$ \\
\hline Nutrient profile & Most complete & $\begin{array}{l}\text { Most vitamins and } \\
\text { minerals, no fat }\end{array}$ & $\begin{array}{l}\text { Few or no vitamins } \\
\text { and minerals and } \\
\text { no fat }\end{array}$ & $\begin{array}{l}\text { Variable depending } \\
\text { on product; contains } \\
\text { PHE }\end{array}$ & $\begin{array}{l}\text { Variable } \\
\text { depending } \\
\text { on product }\end{array}$ \\
\hline $\begin{array}{l}\text { Energy/protein ratio } \\
(\mathrm{kcal} / \mathrm{g} \text { protein })^{b}\end{array}$ & High to medium & Medium to low & Low & Variable & Low \\
\hline $\begin{array}{l}\text { Products designed } \\
\text { for infants }\end{array}$ & $\begin{array}{l}\text { Periflex Infante, } \text { Phenex- }^{\dagger}{ }^{\dagger} \text {, } \\
\text { Phenyl-Free }{ }^{9}\end{array}$ & None & None & None & None \\
\hline $\begin{array}{l}\text { Products designed } \\
\text { for childrenc }\end{array}$ & $\begin{array}{l}\text { Periflex Juniore, }{ }^{\mathrm{e}} \text { Phenex- } \\
2^{\mathrm{f}} \text {, PhenylAde Essentiale, } \\
\text { Phenyl-Free } 2^{g}\end{array}$ & $\begin{array}{l}\text { Lophlexe, PhenylAde 40e, } \\
\text { PKU Coolersh,PKU Gel', } \\
\text { Maxamaid XPe }\end{array}$ & None & $\begin{array}{l}\text { BetterMilk }<12^{i}, \\
\text { Complete bars }<12^{i} \text {, } \\
\text { Restore }^{i}\end{array}$ & None \\
\hline
\end{tabular}

PHE, phenylalanine.

aExamples of products available in the United States as of May 2013. Inclusion in table does not represent endorsement.

bEnergy/protein ratio categories (kcal/g): low, 4-9; medium, 10-19; high, >20.

'Some products are not appropriate for children <4 years; check manufacturer's information for nutrient profile.

dSome products may be used before adolescence, especially if used in combination with other products, depending on clinical circumstances.

eNutricia North America, Gaithersburg, MD.

${ }^{f}$ Abbott Nutrition, Columbus, $\mathrm{OH}$.

gMead Johnson Nutrition, Evansville, IN.

hVitaflo USA, Alexandria, VA.

iCambrooke Foods, Ayer, MA. 


\section{Glycomacropeptide}

GMP is an intact whey protein low in PHE, TYR, histidine, leucine, tryptophan, and arginine. All except PHE must be added as free L-amino acids to provide an appropriate protein source for PAH deficiency. ${ }^{54}$ Although long-term efficacy and growth studies are lacking, a short-term inpatient study found no safety concerns when GMP products replaced amino acid-based medical food. ${ }^{54}$ Various markers pointed to improved protein utilization, ${ }^{54}$ and lower ghrelin concentrations suggested improved satiety when GMP products replaced each subject's usual amino acid-based medical food as the protein source. ${ }^{55}$ Medical food products incorporating GMP are an alternative to PHE-free amino acid formulas. Because GMP contains a small amount of PHE (2-5 mg PHE per gram of protein), ${ }^{54}$ the allowance of PHE from food may need to be reduced to maintain PHE intake within PHE tolerance limits. $^{23}$

\section{Large neutral amino acids}

The theory behind LNAA use as a medical food is described in the ACMG guideline. ${ }^{4}$ LNAAs are not recommended for young children or pregnant women but should be considered for adults with PAH deficiency who are not in good metabolic control and do not adhere to other treatment options. ${ }^{5}$ LNAA therapy has been shown to improve executive function in some adults. ${ }^{56}$ When using LNAAs, $25-30 \%$ of total protein needs are provided by LNAAs, with the remaining $70-75 \%$ coming from dietary protein sources. ${ }^{57}$ Protein intake and plasma amino acids should be monitored to prevent essential amino acid deficiencies. It is difficult to monitor the success of LNAA therapy because blood PHE remains high, and measurement of $\mathrm{PHE}$ concentration in the brain is impractical. Blood and urine melatonin have been suggested as surrogate markers for serotonin and may be useful in monitoring treatment. ${ }^{58}$ Serotonin has been shown to be deficient in individuals with $\mathrm{PAH}$ deficiency who exhibit executive function defects. ${ }^{58}$

\section{Providing dietary PHE}

Because PHE is an essential amino acid, limited amounts from intact protein must be provided for anabolic processes regardless of the medical food chosen. For infants, the source of PHE can be either breast milk ${ }^{59}$ or infant formula (containing DHA/ arachidonic acid). A variety of strategies for introducing breast milk have been described. ${ }^{59}$ Although there is little consensus about the best way to incorporate breast milk into the diet of an infant with PAH deficiency, there is agreement that feeding at the breast, as well as feeding expressed breast milk by bottle, results in good metabolic control. ${ }^{60}$ Later in the first year, breast milk or infant formula is slowly removed in exchange for limited amounts of intact protein from solid foods containing an equivalent amount of PHE.

\section{Tracking dietary PHE}

There is little consensus about the best method for tracking dietary PHE intake. As long as data are available on the PHE content of individual food items, the most precise method of tracking PHE intake is counting milligrams of PHE. An exchange system ( 1 exchange $=15 \mathrm{mg} \mathrm{PHE}$ ) is easier for some patients and families. Those with higher PHE tolerance may be able to achieve good PHE control by counting grams of protein. This has the advantage of allowing the use of food labels as a guide. A more liberal approach of allowing "free" consumption of fruits, vegetables, and low-PHE foods $(<100 \mathrm{mg}$ PHE/100 g) allows for similar blood PHE control to that of other tracking methods. ${ }^{61}$ This system has been used by clinics in Europe with good success but is not common practice in the United States. ${ }^{5}$

\section{Modified low-protein foods}

Individuals with severe forms of PAH deficiency and low PHE tolerance often rely on modified low-protein foods to provide energy and variety in their diets. ${ }^{15}$ Modified low-protein foods, including low-protein breads and pasta, use the starch portion of the grain rather than the higher-protein flour. ${ }^{62}$ It is important to note that these products do not have the usual vitamin enrichment found in regular grain products. As a source of energy, these products can help to prevent weight loss, catabolism, and the resulting elevated blood PHE. ${ }^{15}$ Third-party reimbursement for modified low-protein foods is not universally available..$^{52}$

\section{Sapropterin (tetrahydrobiopterin) therapy}

Sapropterin dihydrochloride (sapropterin) is the pharmaceutical form of tetrahydrobiopterin, a cofactor required for PAH activity. Given in therapeutic doses, sapropterin appears to enhance PAH activity in certain individuals with PAH deficiency. ${ }^{63}$ The ACMG PAH deficiency guideline recommends a trial of sapropterin therapy for all individuals. ${ }^{4}$ The benefits of response fall into two categories: for individuals who are nonadherent or unable to maintain diet restriction and medical food intake, sapropterin may lower blood PHE without further diet modification; and for individuals who maintain blood PHE within the therapeutic range by dietary adherence, sapropterin may allow liberalization of dietary PHE and less medical food intake. $^{64}$

Although sapropterin therapy may support significant dietary liberalization, it seldom allows individuals to maintain appropriate blood PHE without some PHE restriction and medical food. Regular monitoring of blood PHE, dietary adequacy, and nutritional status continue to be essential. Individualized patient counseling includes planning and calculating the diet with a higher PHE or protein allowance, choosing appropriate natural protein sources, reading labels, distributing high-PHE/ intact protein foods throughout the day, meeting micronutrient/vitamin requirements when the medical food prescription is decreased, and understanding the importance of consistent sapropterin dosing. ${ }^{65,66}$ Longer-term follow-up will be necessary to determine whether individuals with PAH deficiency remain adherent to sapropterin and dietary recommendations and if there is an impact on outcome. 


\section{Nutrition counseling and education}

Nutrition counseling and education involve teaching individuals with PAH deficiency and/or their caregivers the importance of the diet in maintaining appropriate blood PHE, normal growth, and health maintenance while ensuring that they have the necessary skills to adhere to the diet throughout the life span. Education techniques and materials must be appropriate for the individual's learning style ${ }^{67}$ access to care, acceptance of the diet, and/or readiness for change. Research into effective education and counseling strategies for PAH deficiency is lacking.

\section{RECOMMENDATIONS}

- $\quad$ Evaluate individual nutritional needs, ability to adhere to recommendations, and access to treatment options when choosing appropriate interventions (medical food, modified low-protein food, sapropterin, and LNAAs) to achieve blood PHE in the target range.

- $\quad$ Provide counseling and education specific to the needs of the individual with PAH deficiency (and/or his/her caregivers) to help maintain appropriate blood PHE throughout the life span.

- $\quad$ Recommend that medical food be consumed throughout the day for optimal metabolic control.

- Include breast milk and/or infant formula as sources of PHE in the diet of an infant with PAH deficiency.

- Track PHE intake by any of several methods, including counting milligrams or exchanges of PHE or grams of protein.

- $\quad$ Consider use of LNAAs in adults with PAH deficiency who are not in good metabolic control and not able to adhere to other treatment options.

- Individualize the diets of responders to sapropterin with appropriate PHE, medical foods, or modified low-protein food intake and/or vitamin/mineral supplementation to ensure adequate nutrient intake.

\section{TREATMENT IN SPECIAL CIRCUMSTANCES} Pregnancy in women with PAH deficiency

High maternal blood PHE is associated with poor outcomes in offspring, including low birth weight, microcephaly, congenital heart defects, and intellectual disability. Maintaining maternal blood PHE between 120 and $360 \mu \mathrm{mol} / \mathrm{l}$ before and during pregnancy results in the best outcome for offspring. ${ }^{2}$ However, $30 \%$ of clinics surveyed recommend $120-240 \mu \mathrm{mol} / \mathrm{l}$ as the target range for maternal blood $\mathrm{PHE} .^{5}$

Most studies have not evaluated the effect of nutrition (beyond maternal blood PHE) on outcomes. In the Maternal PKU Collaborative Study, maternal protein intake and energy were significantly and negatively correlated with blood PHE throughout the entire pregnancy. ${ }^{68}$ Women with low protein intake secondary to inadequate consumption of medical food also had low overall nutrient intake and a higher incidence of congenital anomalies in their offspring. ${ }^{69}$ Adequate energy and fat intake, as well as adequate weight gain, have all been associated with better pregnancy outcomes. ${ }^{68}$ Control of nausea and vomiting, especially in early pregnancy, is key to preventing catabolic weight loss and elevated PHE levels. Neither TYR intake nor blood TYR has been reported to be associated with outcomes in maternal PAH deficiency. ${ }^{70}$ Fat and essential fatty acid intakes may be very low in individuals with PAH deficiency when their medical food contains no fat. DHA supplementation of $200-300 \mathrm{mg} /$ day should be provided to all pregnant women with $\mathrm{PAH}$ deficiency. ${ }^{5}$ Specific monitoring recommendations during pregnancy for women with PAH deficiency are outlined in Table 2. The use of adjunctive therapies in managing blood PHE during pregnancy is a matter of debate. LNAA monotherapy is not recommended, because it does not result in adequate control of blood PHE. Because sapropterin can lower blood PHE, its use should be considered on a case-by-case basis. ${ }^{5}$ Women are encouraged to continue the diet in the postpartum period and can breast-feed their non-PAH-deficient infant regardless of maternal blood PHE levels.

\section{RECOMMENDATIONS}

- Maintain blood PHE between 120 and $360 \mu \mathrm{mol} / \mathrm{l}$ before conception and throughout pregnancy.

- Monitor dietary intake of pregnant women with PAH deficiency to ensure nutrient adequacy.

- Consider sapropterin use on a case-by-case basis for pregnant women who have difficulty adhering to the diet.

- $\quad$ Do not recommend LNAAs for use in pregnant women with PAH deficiency.

\section{Sick days and catabolism}

Infection, inflammation, and injury induce a catabolic state, with increased endogenous protein breakdown and impaired anabolism. For individuals with PAH deficiency, this can lead to increased blood PHE; however, there are no published data, nor is there consensus regarding "sick day" management. Specialized parenteral nutrition solutions have been used when adequate enteral intake is not possible. ${ }^{71}$

\section{Late-treated PAH deficiency}

Improvements in behavior and functioning have been documented in previously untreated individuals with $\mathrm{PAH}$ deficiency who have been placed on diet therapy. ${ }^{72,73}$ In children for whom therapy was delayed, improvement in IQ may occur after nutrition therapy is initiated. ${ }^{72,73}$ Choice of treatment modality should be based on feasibility and effectiveness for the individual patient. Among the concerns are comorbidities, contraindications due to prescribed medications, and limited access to care.

\section{PSYCHOSOCIAL SUPPORT}

Treatment for PAH deficiency is complex, and adherence to recommendations diminishes with age. ${ }^{74}$ The companion ACMG $\mathrm{PAH}$ deficiency treatment guideline $\mathrm{e}^{4}$ discusses the problems and challenges faced by individuals with $\mathrm{PAH}$ deficiency as they transition into adulthood. ${ }^{4}$ Adherence improves if individuals have a social support system; an understanding of the benefits of treatment; access to appropriate care, medical foods and 
modified low-protein foods; and a belief that PAH deficiency is manageable. ${ }^{75}$ Special support and advocacy are frequently necessary to secure access to the medical foods required by individuals with PAH deficiency. ${ }^{2,51}$ Creative approaches for clinic- and community-based programs, such as age-specific educational programs, camps, and other support programs, hold promise for improving adherence and quality of life.

\section{RECOMMENDATIONS}

- $\quad$ Ensure access to medical and modified low-protein foods.

- Provide connections to sources of social support, such as camps, mentoring programs, and other support groups.

\section{CONCLUSION}

Nutrition management of PAH deficiency has resulted in remarkable outcomes for individuals who have benefitted from early diagnosis and treatment. These positive outcomes are the sum of dedicated research, clinical attentiveness, and patient adherence. Although much has been learned about providing proper nutrition on a PHE-restricted diet, many aspects of diet and health in individuals with PAH deficiency require further investigation. These include issues such as adequacy of absorption of nutrients from medical foods, bone density, weight status, long-term neurocognitive outcomes, and oxidative stress, as well as the roles of less available nutrients (e.g., menaquinone and vitamin $\mathrm{K}_{2}$ ) and functional nonnutrients (e.g., nucleosides, nucleotides, pre- and probiotics, and polyphenolic compounds). How to balance nutrition management with other treatments, such as LNAAs, sapropterin, and PEGylated phenylalanine lyase, and the impact of genotype on treatment are still being explored. Continued research should also examine approaches that promote adherence to therapy. The health-care system must ensure that individuals with PAH deficiency have access to the care necessary for optimal outcomes.

These recommendations for the nutrition management of individuals with PAH deficiency reflect the latest in scientific understanding and clinical practice. The workgroup is continuing, with evidence and consensus methodology, to develop comprehensive nutritional management guidelines, resources, and tools for PAH deficiency that will be made available on the Genetic Metabolic Dietitians International and the Southeast Regional Genetics Collaborative websites.

\section{ACKNOWLEDGMENTS}

We gratefully acknowledge the National Institutes of Health $(\mathrm{NIH})$ for convening the PKU Scientific Review Conference, the contributions of the members of the Diet Control and Management and Maternal PKU Workgroups, and the guidance provided by the NIH Office of Dietary Supplements. We acknowledge members of the Genetic Metabolic Dietitians International PKU Guideline Development Workgroup who provided their expertise in nutrition management of PAH deficiency for this article. Finally, we acknowledge Teresa Douglas and Kathryn Coakley for their assistance in editing. This work was partially supported by a grant from the Maternal and Child Health Bureau, Health Resources and Services Administration, Department of Health and Human Services (grant H46- MC24090).

\section{DISCLOSURE}

R.H.S., F.R., A.C., S.C.V.C., and J.V. have participated in and/or received research funding for clinical trials related to PAH deficiency. A.C. has participated in and received research funding for studies related to PAH deficiency and is a consultant for and serves on advisory boards for BioMarin Pharmaceuticals and Merck and Company. S.M. serves on the advisory board for the PKU Demographics, Outcomes and Safety Registry (PKUDOS) sapropterin postmarketing patient registry and is a consultant dietitian for BioMarin. The other authors declare no conflict of interest.

\section{REFERENCES}

1. Agency for Healthcare Research and Quality. Comparative Effectiveness of Treatment for Phenylketonuria (PKU). Comparative Effectiveness Review No. 56. (Prepared by the Vanderbilt Evidence-Based Practice Center under Contract No. 290-2007-10065-I.) AHRQ Publication No. 12-EHC035-EF. 2011; http://www.effectivehealthcare.ahrq.gov/reports/final.cfm.

2. National Institutes of Health. National Institutes of Health Consensus Development Conference Statement: phenylketonuria: screening and management, October 16-18, 2000. Pediatrics 2001;108:972-982.

3. Recommendations on the dietary management of phenylketonuria. Report of Medical Research Council Working Party on Phenylketonuria. Arch Dis Child 1993;68:426-427

4. Vockley J, Andersson H, Antshel KM, et al. Phenylalanine hydroxylase deficiency diagnosis and management guideline. Genet Med, e-pub ahead of print 2 January 2014

5. GMDI Delphi Survey: Genetic Metabolic Dietitians International and Southeast Regional Newborn Screening and Genetics Collaborative; 2013.

6. Singh RH, Rohr F, Splett PL. Bridging evidence and consensus methodology for inherited metabolic disorders: creating nutrition guidelines. J Eval Clin Pract 2011;19:584-590.

7. Waisbren SE, Noel K, Fahrbach K, et al. Phenylalanine blood levels and clinical outcomes in phenylketonuria: a systematic literature review and meta-analysis. Mol Genet Metab 2007;92:63-70.

8. MacDonald A, Rylance G, Hall SK, Asplin D, Booth IW. Factors affecting the variation in plasma phenylalanine in patients with phenylketonuria on diet. Arch Dis Child 1996;74:412-417.

9. Sharman R, Sullivan KA, Young RM, McGill JJ. Tyrosine monitoring in children with early and continuously treated phenylketonuria: results of an international practice survey. J Inherit Metab Dis 2010;33(suppl 3):S417-S420.

10. Luciana M, Sullivan J, Nelson CA. Associations between phenylalanine-totyrosine ratios and performance on tests of neuropsychological function in adolescents treated early and continuously for phenylketonuria. Child Dev 2001;72:1637-1652.

11. Blau N, Hennermann JB, Langenbeck U, Lichter-Konecki U. Diagnosis, classification, and genetics of phenylketonuria and tetrahydrobiopterin (BH4) deficiencies. Mol Genet Metab 2011;104(suppl):S2-S9.

12. van Spronsen FJ, van Rijn M, Dorgelo B, et al. Phenylalanine tolerance can already reliably be assessed at the age of 2 years in patients with PKU. J Inherit Metab Dis 2009;32:27-31

13. MacLeod EL, Gleason ST, van Calcar SC, Ney DM. Reassessment of phenylalanine tolerance in adults with phenylketonuria is needed as body mass changes. Mo/ Genet Metab 2009;98:331-337.

14. Hennermann JB, Roloff S, Gebauer C, Vetter B, von Arnim-Baas A, Mönch E. Long-term treatment with tetrahydrobiopterin in phenylketonuria: treatment strategies and prediction of long-term responders. Mol Genet Metab 2012;107:294-301

15. Macleod EL, Ney DM. Nutritional management of phenylketonuria. Ann Nestle Eng 2010;68:58-69

16. Thiele AG, Weigel JF, Ziesch B, et al. Nutritional changes and micronutrient supply in patients with phenylketonuria under therapy with tetrahydrobiopterin (BH(4)). JIMD Rep 2013;9:31-40. 
17. Hanley WB. Non-PKU mild hyperphenylalaninemia (MHP)-the dilemma. Mol Genet Metab 2011;104:23-26.

18. Huemer M, Huemer C, Möslinger D, Huter D, Stöckler-Ipsiroglu S. Growth and body composition in children with classical phenylketonuria: results in 34 patients and review of the literature. J Inherit Metab Dis 2007;30:694-699.

19. Acosta PB, Yannicelli S, Singh R, et al. Nutrient intakes and physical growth of children with phenylketonuria undergoing nutrition therapy. J Am Diet Assoc 2003;103:1167-1173.

20. Acosta PB. Nutrition management of patients with inherited metabolic disorders of aromatic amino acid metabolism. In: Acosta PB (ed). Nutrition Management of Patients With Inherited Metabolic Disorders. Jones and Bartlett Publishers: Sudbury, MA, 2010:126-129.

21. Metges CC, El-Khoury AE, Selvaraj AB, et al. Kinetics of L-[1-(13)C]leucine when ingested with free amino acids, unlabeled or intrinsically labeled casein. Am J Physiol Endocrinol Metab 2000;278:E1000-E1009.

22. Gropper SS, Acosta PB. Effect of simultaneous ingestion of L-amino acids and whole protein on plasma amino acid and urea nitrogen concentrations in humans. JPEN J Parenter Enteral Nutr 1991;15:48-53.

23. van Calcar SC, Ney DM. Food products made with glycomacropeptide, a lowphenylalanine whey protein, provide a new alternative to amino acid-based medical foods for nutrition management of phenylketonuria. J Acad Nutr Diet 2012;112:1201-1210.

24. University of Washington PKU Clinic Management Guidelines. 2013. http:// depts.washington.edu/pku/pdfs/Management_Guidelines_Brochure_0308. pdf. Accessed 12 March 2013.

25. Rocha JC, Almeida MF, Carmona C, et al. The use of prealbumin concentration as a biomarker of nutritional status in treated phenylketonuric patients. Ann Nutr Metab 2010;56:207-211.

26. Arnold GL, Vladutiu CJ, Kirby RS, Blakely EM, Deluca JM. Protein insufficiency and linear growth restriction in phenylketonuria. J Pediatr 2002;141:243-246.

27. Smith ML, Hanley WB, Clarke JT, et al. Randomised controlled trial of tyrosine supplementation on neuropsychological performance in phenylketonuria. Arch Dis Child 1998;78:116-121.

28. Hanley WB, Lee AW, Hanley AJ, et al. "Hypotyrosinemia" in phenylketonuria. Mol Genet Metab 2000;69:286-294.

29. Kalsner LR, Rohr FJ, Strauss KA, Korson MS, Levy HL. Tyrosine supplementation in phenylketonuria: diurnal blood tyrosine levels and presumptive brain influx of tyrosine and other large neutral amino acids. J Pediatr 2001;139:421-427.

30. Rocha JC, van Spronsen FJ, Almeida MF, et al. Dietary treatment in phenylketonuria does not lead to increased risk of obesity or metabolic syndrome. Mol Genet Metab 2012;107:659-663.

31. Dietary Reference Intakes for Energy, Carbohydrates, Fiber, Fat, Fatty Acids, Cholesterol, Protein, and Amino Acids. The National Academies Press: Washington, DC, 2005

32. Acosta PB, Yannicelli S, Singh R, et al. Intake and blood levels of fatty acids in treated patients with phenylketonuria. J Pediatr Gastroenterol Nutr 2001;33:253-259.

33. Cleary MA, Feillet F, White FJ, et al. Randomised controlled trial of essential fatty acid supplementation in phenylketonuria. Eur J Clin Nutr 2006;60: 915-920.

34. Alexander FW, Clayton BE, Delves HT. Mineral and trace-metal balances in children receiving normal and synthetic diets. Q J Med 1974;43:89-111.

35. Jochum F, Terwolbeck K, Meinhold H, Behne D, Menzel H, Lombeck I. Effects of a low selenium state in patients with phenylketonuria. Acta Paediatr 1997:86:775-777.

36. Acosta PB, Yannicelli S, Singh RH, Elsas $\sqcup 2$ nd, Mofidi S, Steiner RD. Iron status of children with phenylketonuria undergoing nutrition therapy assessed by transferrin receptors. Genet Med 2004;6:96-101.

37. Arnold GL, Kirby R, Preston C, Blakely E. Iron and protein sufficiency and red cell indices in phenylketonuria. J Am Coll Nutr 2001;20:65-70.

38. Walter JH. Vitamin B12 deficiency and phenylketonuria. Mol Genet Metab 2011;104(suppl):S52-S54

39. Hanley WB, Feigenbaum AS, Clarke JT, Schoonheyt WE, Austin VJ. Vitamin B12 deficiency in adolescents and young adults with phenylketonuria. Eur J Pediatr 1996:155(suppl 1):S145-S147.

40. Hvas AM, Nexo E, Nielsen JB. Vitamin B12 and vitamin B6 supplementation is needed among adults with phenylketonuria (PKU). J Inherit Metab Dis 2006:29:47-53

41. Prince AP, Leklem JE. Vitamin B-6 status of school-aged patients with phenylketonuria. Am J Clin Nutr 1994;60:262-268.

42. Allen JR, Humphries IR, Waters $\mathrm{DL}$, et al. Decreased bone mineral density in children with phenylketonuria. Am J Clin Nutr 1994;59:419-422.
43. Hillman L, Schlotzhauer $C$, Lee $D$, et al. Decreased bone mineralization in children with phenylketonuria under treatment. Eur J Pediatr 1996;155(supp 1):S148-S152.

44. Pérez-Dueñas B, Cambra FJ, Vilaseca MA, Lambruschini N, Campistol J, Camacho JA. New approach to osteopenia in phenylketonuric patients. Acta Paediatr 2002;91:899-904.

45. Porta F, Mussa A, Zanin A, Greggio NA, Burlina A, Spada M. Impact of metabolic control on bone quality in phenylketonuria and mild hyperphenylalaninemia. $J$ Pediatr Gastroenterol Nutr 2011;52:345-350.

46. Al-Qadreh A, Schulpis KH, Athanasopoulou H, Mengreli C, Skarpalezou A, Voskaki I. Bone mineral status in children with phenylketonuria under treatment. Acta Paediatr 1998;87:1162-1166.

47. Millet $P$, Vilaseca MA, Valls $C$, et al. Is deoxypyridinoline a good resorption marker to detect osteopenia in phenylketonuria? Clin Biochem 2005;38:11271132

48. Burrage LC, McConnell J, Haesler R, et al. High prevalence of overweight and obesity in females with phenylketonuria. Mol Genet Metab 2012;107:43-48

49. Belloso LM, Lowitt MH. Cutaneous findings in a 51-year-old man with phenylketonuria. J Am Acad Dermatol 2003;49(2 Suppl Case Reports):S190S192.

50. Koch R, Burton B, Hoganson G, et al. Phenylketonuria in adulthood: a collaborative study. J Inherit Metab Dis 2002;25:333-346.

51. Brumm VL, Bilder D, Waisbren SE. Psychiatric symptoms and disorders in phenylketonuria. Mol Genet Metab 2010;99(suppl 1):S59-S63.

52. Berry SA, Kenney MK, Harris KB, et al. Insurance coverage of medical foods for treatment of inherited metabolic disorders. Genet Med 2013;15:978-982.

53. Haffner ME. Applications of the orphan drug act to special patient populations. Drug Inf J 1994;28:495-503

54. van Calcar SC, MacLeod EL, Gleason ST, et al. Improved nutritional management of phenylketonuria by using a diet containing glycomacropeptide compared with amino acids. Am J Clin Nutr 2009;89:1068-1077.

55. MacLeod EL, Clayton MK, van Calcar SC, Ney DM. Breakfast with glycomacropeptide compared with amino acids suppresses plasma ghrelin levels in individuals with phenylketonuria. Mol Genet Metab 2010;100:303-308.

56. Schindeler S, Ghosh-Jerath S, Thompson S, et al. The effects of large neutral amino acid supplements in PKU: an MRS and neuropsychological study. Mol Genet Metab 2007;91:48-54.

57. Ahring KK. Large neutral amino acids in daily practice. J Inherit Metab Dis 2010;33(suppl 3):S187-S190.

58. Yano S, Moseley K, Azen C. Large neutral amino acid supplementation increases melatonin synthesis in phenylketonuria: a new biomarker. J Pediatr 2013:162:999-1003.

59. van Rijn M, Bekhof J, Dijkstra T, Smit PG, Moddermam P, van Spronsen FJ. A different approach to breast-feeding of the infant with phenylketonuria. Eur J Pediatr 2003;162:323-326.

60. Kanufre VC, Starling AL, Leão E, et al. Breastfeeding in the treatment of children with phenylketonuria. J Pediatr (Rio J) 2007;83:447-452.

61. Zimmermann $M$, Jacobs $P$, Fingerhut $R$, et al. Positive effect of a simplified diet on blood phenylalanine control in different phenylketonuria variants, characterized by newborn BH4 loading test and PAH analysis. Mol Genet Metab 2012;106:264-268

62. Independence Blue Cross. Medical Foods, Low-Protein Modified Food Products, Enteral Nutrition, and Nutritional Formulas. 2013. http://medpolicy.ibx.com/ policies/MPI.nsf/e94faffabc7b0da68525695e0068df65/8369d0c69dd8e3f08 525797d00579787! OpenDocument. Accessed 11 March 2013

63. Blau N, Erlandsen $\mathrm{H}$. The metabolic and molecular bases of tetrahydrobiopterinresponsive phenylalanine hydroxylase deficiency. Mol Genet Metab 2004:82:101-111.

64. Burton BK, Grange DK, Milanowski A, et al. The response of patients with phenylketonuria and elevated serum phenylalanine to treatment with oral sapropterin dihydrochloride (6R-tetrahydrobiopterin): a phase II, multicentre, open-label, screening study. J Inherit Metab Dis 2007:30:700-707.

65. Singh RH, Quirk ME. Using change in plasma phenylalanine concentrations and ability to liberalize diet to classify responsiveness to tetrahydrobiopterin therapy in patients with phenylketonuria. Mol Genet Metab 2011;104:485-491.

66. Cunningham $\mathrm{A}$, Bausell $\mathrm{H}$, Brown $\mathrm{M}$, et al. Recommendations for the use of sapropterin in phenylketonuria. Mol Genet Metab 2012;106:269-276.

67. Bernstein $L E$, Helm JR, Rocha JC, et al. Nutrition education tools used in phenylketonuria: clinician, parent and patient perspectives from three international surveys. J Hum Nutr Diet 2013; e-pub ahead of print 23 April 2013 
68. Acosta PB, Matalon K, Castiglioni L, et al. Intake of major nutrients by women in the Maternal Phenylketonuria (MPKU) Study and effects on plasma phenylalanine concentrations. Am J Clin Nutr 2001;73:792-796.

69. Michals-Matalon K, Platt LD, Acosta P P, Azen C, Walla CA. Nutrient intake and congenital heart defects in maternal phenylketonuria. Am J Obstet Gynecol 2002;187:441-444

70. Koch R, Hanley W, Levy H, et al. The Maternal Phenylketonuria Internationa Study: 1984-2002. Pediatrics 2003;112(Pt 2):1523-1529.

71. Salvarinova-Zivkovic R, Hartnett C, Sinclair G, et al. The use of parenteral nutrition for the management of PKU patient undergoing chemotherapy for lymphoma: a case report. Mol Genet Metab 2012;105:571-574.

72. Lee PJ, Amos A, Robertson L, et al. Adults with late diagnosed PKU and severe challenging behaviour: a randomised placebo-controlled trial of a phenylalanine-restricted diet. J Neurol Neurosurg Psychiatr 2009;80: $631-635$
73. Grosse SD. Late-treated phenylketonuria and partial reversibility of intellectual impairment. Child Dev 2010;81:200-211.

74. Walter $\mathrm{JH}$, White FJ. Blood phenylalanine control in adolescents with phenylketonuria. Int J Adolesc Med Health 2004;16:41-45.

75. Finkelson L, Bailey I, Waisbren SE. PKU adults and their return to diet predicting diet continuation and maintenance. J Inherit Metab Dis 2001; 24:515-516.

(c) (i) @) This work is licensed under a Creative
Derivative Works 3.0 License. To view a copy of this license,
visit http://creativecommons.org/licenses/by-nc-nd/3.0/

